\title{
Development of Dynamic Simulation of Gas and Condensate Pipeline Network
}

\author{
Zulfan Adi Putra*, Zalina Harun and Shahrul Azman Zainal Abidin \\ PETRONAS Group Technical Solutions (Process Simulation and Optimization), Kuala Lumpur, 50088, Malaysia
}

\begin{abstract}
Developing a steady operation of gas and condensate value chain is an important task to maintain stable productions of oil \& gas industries. In this regard, PETRONAS continues to improve its production facilities by utilizing process modelling and simulation via Symmetry $\mathrm{iCON} \circledast$ as one of its main engineering tools. In this work, Symmetry iCON® pipe network solver was used to build a dynamic simulation model for gas and condensate pipeline network in Malaysian Peninsular region. One-month data of December 2018 has been used to validate the model. Then it was utilized to predict the data in January 2019 to further evaluate the applicability of the model. Some valuable observations included the significance of properties estimation of a pseudo component of $\mathrm{C} 6+$ in terms of thermodynamic and transport properties. Due to lack of data monitoring of the condensate in some terminals, this property estimation became very crucial while at the same time difficult to validate. Nonetheless, the model can predict the data within the range of error of $4-6 \%$. In the future, when more data is available, the properties can be easily tuned to better represent the reality.
\end{abstract}

\section{INTRODUCTION}

Oil and gas production consist of various interconnections between gas or oil wells, pipelines, platforms, and terminals where the oil and gas are treated and furtfher distributed. Malaysia Oil and Gas exploration and production facilities are owned and operated by PETRONAS [1]. In 2015, the region of Peninsular Malaysia supplied about $82 \%$ of the total domestic demand [2].

Nowadays, companies in the oil and gas industries have realized the importance of technologies and their impacts in optimizing the overall operation process [3]. Among these technologies is process simulation software where they can be used, among others, to simulate different scenarios of supply and demands of oil and gas productions, maximizing throughput and/or profit, minimizing cost, and many more.

PETRONAS understands the clear needs of utilizing technologies, e.g. use of process simulation software, to support maintaining the quantity and the quality of its oil and gas productions. In this regard, PETRONAS uses Symmetry $\mathrm{iCON} \circledast$ software that has been used in many applications such as vapour liquid equilibrium [4], biomass gasification [5], bio oil upgrading [6], utility optimization [7], and many other internal applications for modelling their worldwide refineries, petrochemicals, and chemical plants.

Modelling and optimization of natural gas networks have been done such as minimizing fuel gas consumption of compressors to satisfy natural gas demands [8], [9], operational optimization [10], coping with transient stages of gas supply in China [11], multi period optimization [12], reliability [13], and risk management [14]. Many of these previous works were conducted using steady state calculations. Other notable works in studying dynamic behaviour covers upset conditions like slugging [15] or different pipeline inclinations [16]. Nonetheless, all of these studies were developed using their own specific gas distribution networks since no network is the same.

In this work, to support reliable and improved gas production in Malaysian Peninsular region, PETRONAS gas pipeline networks needed to be modelled and further used to optimize the gas productions. PETRONAS Symmetry $\mathrm{iCON} ®$ software has been used as the platform for this modelling work. Existing pipeline configurations were used as the basis along with other operational data such as gas compositions, temperature, pressure, and flowrate. The modelling work was done in dynamic mode to account for transient situations and evaluate different operational scenarios.

\section{Methodology}

Flowchart of the methodology is shown in Figure 1. Relevant data were first collected. This included components, their compositions and operating conditions, as well as existing pipeline configuration. Then, the model was the developed and validated using operational data from December 2018. Then the model was tested against data from January 2019. Finally, some 
insights on the model and the data were observed and evaluated.

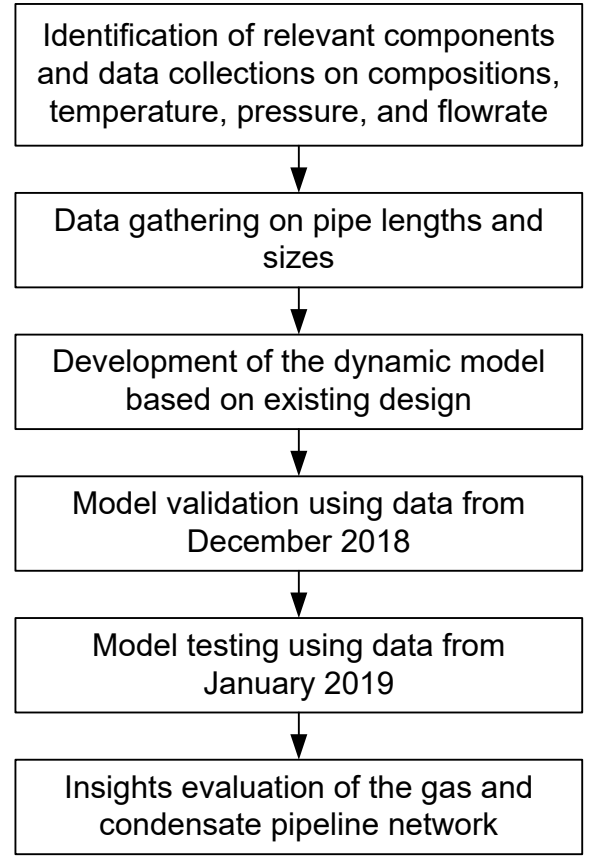

Figure 1. Work Methodology.

The model was developed by using Symmetry iCON® Process Simulation Software built 350. Network solver approach was used as the calculation method. There were four sections of the pipeline network modelled independently, which then combined to make an overall model. These sections were Section A, Section B, Section C, and Section D models. Due to confidentiality issues, all names were replaced with general terms. This approach was taken to ease the model development rather than making a whole complete model from scratch. On the other hand, model validation and testing were done separately for these four sections. The overall scope for the model development is shown in Figure 2.

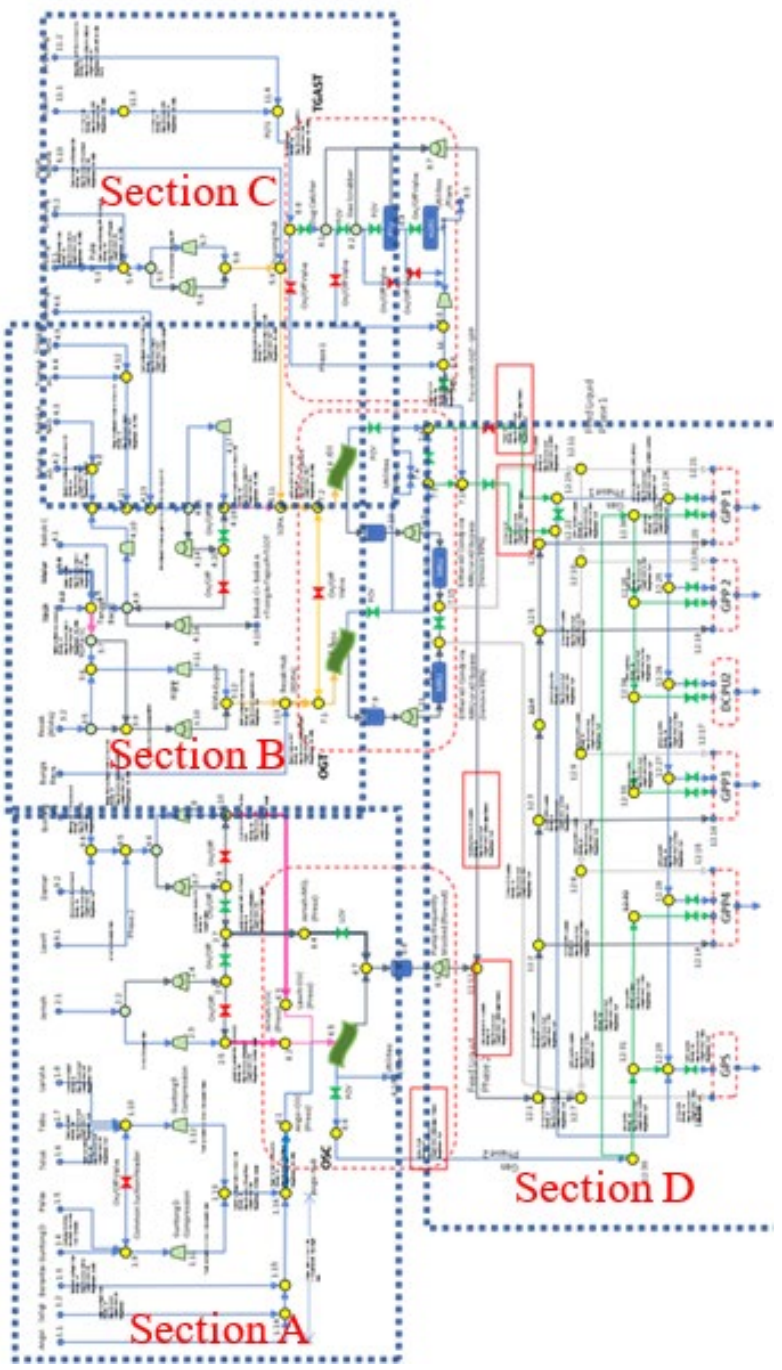

Figure 2. The gas and condensate network to model.

\section{Data, Assumptions, and Model Boundaries}

Some of the data used in the model is shown in Table 1. In this paper, all names of the wells or platforms are replaced with generic terms. Only few data are shown throughout the paper to show the flow of the article.

Table 1. Some of the data (in moles percent) used in the model.

\begin{tabular}{|c|c|c|c|c|}
\hline Components & Well 1 & Well 2 & Well 3 & Well 4 \\
\hline Methane & 88.3725 & 88.3725 & 88.4343 & 85.9194 \\
\hline Ethane & 5.8987 & 5.8987 & 4.7543 & 6.4186 \\
\hline Propane & 1.7537 & 1.7537 & 2.7474 & 2.3310 \\
\hline i-Butane & 0.5081 & 0.5081 & 0.9645 & 0.5766 \\
\hline n-Butane & 0.3645 & 0.3645 & 0.5633 & 0.5006 \\
\hline i-Pentane & 0.1945 & 0.1945 & 0.0095 & 0.2409 \\
\hline n-Pentane & 0.1195 & 0.1195 & 0.0049 & 0.1508 \\
\hline
\end{tabular}




\begin{tabular}{|c|c|c|c|c|}
\hline $\mathrm{C} 6+$ & 0.4494 & 0.4494 & 0.0033 & 0.3430 \\
\hline $\mathrm{N}_{2}$ & 0.1496 & 0.1496 & 0.6210 & 0.0898 \\
\hline $\mathrm{CO}_{2}$ & 2.1896 & 2.1896 & 1.8975 & 3.4291 \\
\hline
\end{tabular}

Advanced Peng-Robinson was selected as the thermodynamic model within the Symmetry iCON® thermodynamic packages. This model is an enhanced version of the original Peng-Robinson model, which is adjusted for natural gas applications [17]. Gas densities were then calculated to validate this Advanced PengRobinson model. The results are shown in Table 2 and it is shown that the selected thermodynamic model is acceptable.

Table 2. Advanced Peng-Robinson model validation via gas densities calculations (only few results are shown here).

\begin{tabular}{|l|c|l|c|}
\hline Field Name & Month & $\begin{array}{l}\text { Measured } \\
\text { densities } \\
\left(\mathrm{kg} / \mathrm{Sm}^{3}\right)\end{array}$ & $\begin{array}{l}\text { Predicted } \\
\text { densities using } \\
\text { Symmetry } \\
\text { iCON } ® \text { at } 15^{\circ} \mathrm{C}, \\
\text { 1 atm (Int. } \\
\text { Standard Metric } \\
\text { Conditions for } \\
\text { Natural Gas) }\end{array}$ \\
\hline Platform A & 1-Dec-18 & 0.93943 & 0.9433 \\
\hline Platform B & 1-Dec-18 & 0.856523 & 0.8595 \\
\hline Platform C & 1-Dec-18 & 1.540857 & 1.506 \\
\hline Platform D & 1-Dec-18 & 0.837127 & 0.8402 \\
\hline Platform E & 1-Dec-18 & 0.817616 & 0.8198 \\
\hline Platform F & 1-Dec-18 & 0.808428 & 0.811 \\
\hline Platform G & 1-Dec-18 & 0.873182 & 0.8749 \\
\hline Platform H & 1-Jan-19 & 0.665543 & 0.9259 \\
\hline Platform I & 1-Dec-18 & 0.875609 & 0.8787 \\
\hline Platform J & 1-Dec-18 & 0.791683 & 0.7919 \\
\hline
\end{tabular}

Due to unknown information from the field, properties of $\mathrm{C} 6+$ component were estimated based on its typical density and molecular weight of $\mathrm{C}^{+}+$of common natural gas. In this work, the density used was $824 \mathrm{~kg} / \mathrm{m}^{3}$ and the molecular weight was $120 \mathrm{gr} / \mathrm{mol}$. These numbers are on the higher ends of C6-C7 components which are $660-670 \mathrm{~kg} / \mathrm{m}^{3}$ and $86-100$ $\mathrm{gr} / \mathrm{mol}$ of density and molecular mass, respectively. An important note here is that with these numbers, the estimated production of condensate could be higher than the actual conditions, which unfortunately cannot be validated at the time of this work was conducted. Based on these two inputs, Symmetry iCON® then predicted the remaining properties of $\mathrm{C} 6+$ as follows and it is clearly seen that the predicted $\mathrm{C}^{+}+$properties are consistently on the higher end of the C6-C7 spectrum:

- normal boiling point of $150^{\circ} \mathrm{C}$. This number is above the higher end of the spectrum of $\mathrm{C} 6-\mathrm{C} 7$ $\left(68-98^{\circ} \mathrm{C}\right)$.

- $\mathrm{Pc}=3050 \mathrm{kPa}$. This number is above the higher end of the spectrum of C6-C7 (3020-2740 kPa).
- Vc $=0.443 \mathrm{~m}^{3} / \mathrm{mol}$. This number is above the higher end of the spectrum of C6-C7 (0.37$0.425 \mathrm{~m}^{3} / \mathrm{mol}$ ).

- Tc $=352^{\circ} \mathrm{C}$. This number is above the higher end of the spectrum of C6-C7 $\left(234-267^{\circ} \mathrm{C}\right)$.

- $\mathrm{Zc}=0.2597$. This number is close to your number $(0.250)$.

$-\mathrm{w}=0.322$. This number is at the higher end of the spectrum of C6-C7 (0.296-0.35).

There are some other assumptions and simulation boundaries used in the development of the model that cannot be shown here due to space limitations. Interested readers can contact the authors for more information.

\section{Results and Discussion}

\subsection{Section A, B, and D model}

Models for Section A, B, and D are not shown in this paper due to space limitations. Section B consists of a bigger terminal compared to Section $\mathrm{A}$ and $\mathrm{C}$, and hence, the figure will also be too compact to be shown as already indicated in Figure 2.

\subsection{Section C model}

Figure 3 shows the model developed for Section C. The upper part of the model shows the wells while the lower part is the slug catcher in the offshore terminal. This Section $\mathrm{C}$ is the simplest one with only two wells combined, travel for more than $100 \mathrm{~km}$, and then arrive at a platform for further treatment.

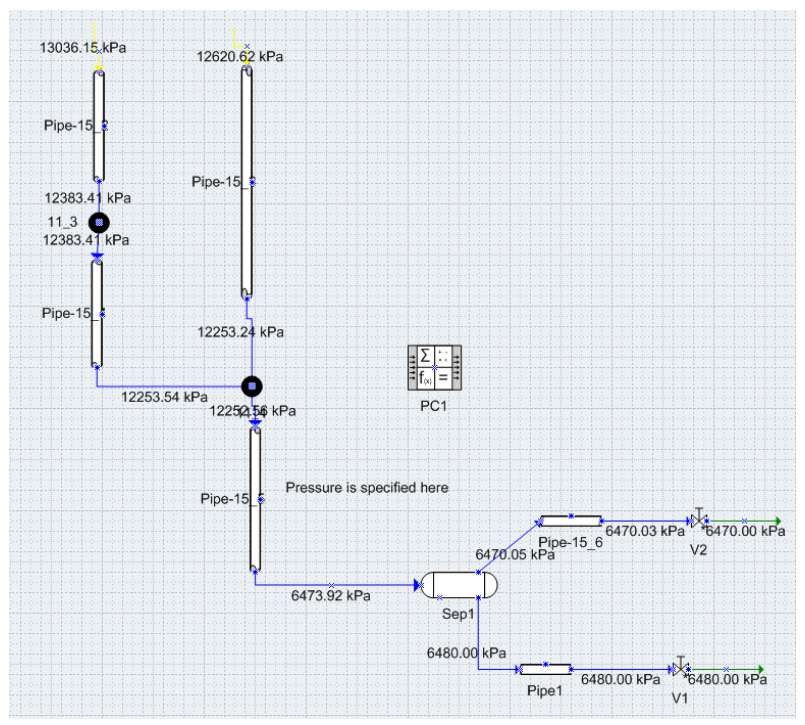

Figure 3. Model developed for Section C.

The above model was used to simulate the data from December 2018 (development) and January 2019 (testing) and the results are shown in Figure 4 and Figure 5 , respectively. It can be seen from the figures that the 
developed model can predict the data very well. In these figures, the results of other model are also shown for PETRONAS internal use and comparison. Overall, the differences between the model and the data are about 2$4 \%$.

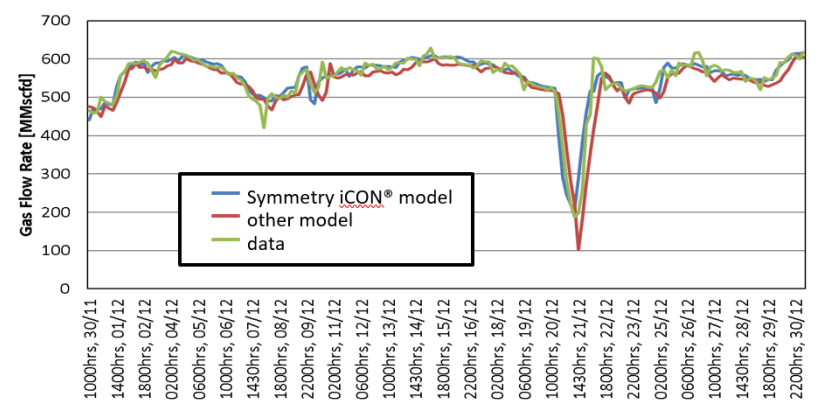

Figure 4. Predicted export gas flow compared with the data in December 2018.

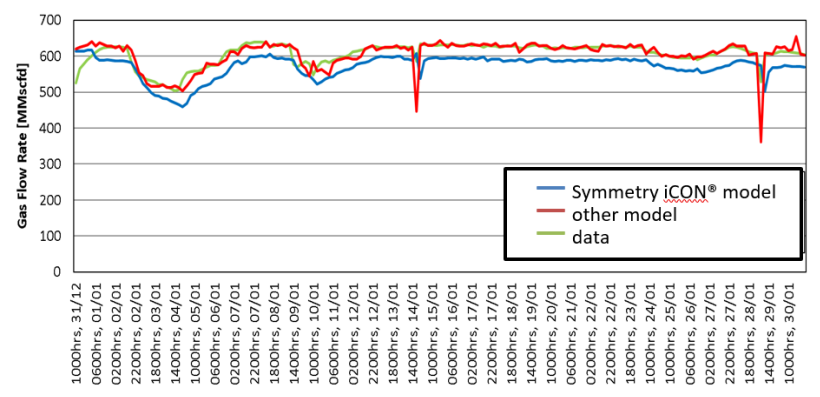

Figure 5. Predicted export gas flow compared with the data in January 2019.

\subsection{Section A condensate estimation}

In Section A, it was reported that condensate is produced, and the operators only run the condensate pump when the liquid level is higher than the specified $30 \%$ level. There is no recorded information about when or how frequent (given the flowrate data) that the pump is run. On the other hand, the model predicts that there is continuous production of condensate due to the pressure drop given the estimated properties of the pseudo $\mathrm{C}^{+}+$ component. The condensate production is shown in Figure 6 .

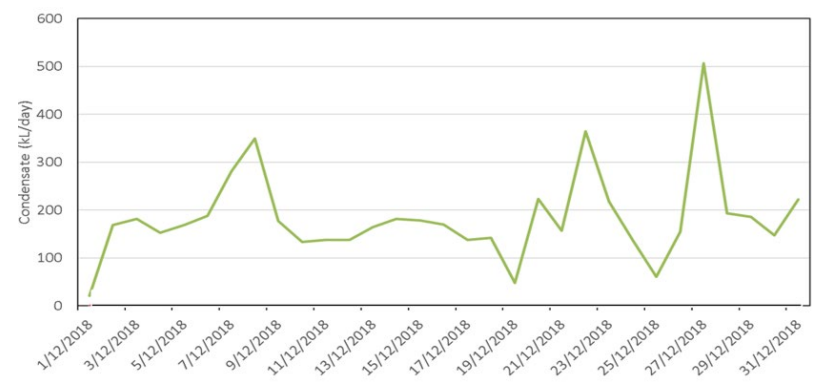

Figure 6. Condensate produced daily as predicted by the model.
Further thermodynamic analysis via phase envelope has shown that at the terminal condition of about 84 bara, at typical arriving temperature of $26{ }^{\circ} \mathrm{C}$, some condensate is formed. It is approximately about $13 \mathrm{~m}^{3} / \mathrm{hr}$ of condensates. This number is insignificant compared to the amount of gas which is approximately 900-1000 MMscfd. Nonetheless, the exact amount of the condensate cannot be confirmed and hence, the properties of $\mathrm{C}^{+}+$cannot be adjusted accordingly. Hence, in the future, when such data is available, the properties of $\mathrm{C} 6+$ can be further improved.

\section{Conclusion and Recommendation}

A dynamic simulation model for gas and condensate pipeline network in Malaysian Peninsular region has been developed using Symmetry iCON®. The results of the model are in agreement with the operational data from December 2018 (for model development) until January 2019 (for model testing). The difference between the model and the data is about $4-6 \%$. This difference is valid for operations without operator manual interventions. Estimated properties of a pseudo component of $\mathrm{C} 6+$ are very important to better reflect the production of condensates in some terminals. Due to the lack of condensate data, the estimated properties cannot be easily adjusted. Hence, in the future, when additional data is available, the properties of this pseudo C6+ component should be adjusted.

Special thanks to Malaysia Petroleum Management (MPM) and PETRONAS Group Technical Data (GTD) for making this study possible.

\section{References}

[1] "US Energy Information Administration. Country Analysis Brief: Malaysia." US Energy Information Administration, 2017.

[2] "Malaysia: Natural Gas Industry Annual Review 2016 Ed." Malaysian Gas Association, 2016.

[3] R. and M. Itd, "Process Simulation Software in Oil and Gas Market - Global Industry Analysis, Size, Share, Growth, Trends, and Forecast 2017-2027." [Online]. Available: https://www.researchandmarkets.com/reports/48510 86/process-simulation-software-in-oil-and-gasmarket. [Accessed: 28-Jan-2020].

[4] S. R. S. Abdullah, M. Markom, and M. I. Razak, "Application of $\mathrm{iCON} ®$ software in solving vaporliquid equilibrium problems," in International Conference on Engineering Education and International Conference on Education and Educational Technologies - Proceedings, 2011, pp. 209-214.

[5] M. M. Ahmad, M. K. Yunus, and A. Inayat, "Simulation of Gasification with In-situ Carbon Dioxide Adsorption of Empty Fruit Bunch into Hydrogen," presented at the International Conference on Chemical Engineering and 
Application (CCEA 2010), Singapore, 2010, pp. 126-131.

[6] M. M. Ahmad, M. F. R. Nordin, and M. T. Azizan, "Upgrading of Bio-Oil into High-Value Hydrocarbons via Hydrodeoxygenation," American Journal of Applied Sciences, vol. 7, no. 6, pp. 746755, Jun. 2010, doi: 10.3844/ajassp.2010.746.755.

[7] J. Currie, "Practical applications of industrial optimization: from high-speed embedded controllers to large discrete utility systems," 2014.

[8] T. Rodríguez, D. Sarabia, M. Valbuena, and C. de Prada, "Modelling and Optimization of Natural Gas Networks," in Computer Aided Chemical Engineering, vol. 33, J. J. Klemeš, P. S. Varbanov, and P. Y. Liew, Eds. Elsevier, 2014, pp. 367-372.

[9] Z. Zhang and X. Liu, "Study on optimal operation of natural gas pipeline network based on improved genetic algorithm," Advances in Mechanical Engineering, vol. 9, no. 8, p. 1687814017715981 , Aug. 2017, doi: 10.1177/1687814017715981.

[10] "Optimize an integrated natural gas production and distribution network." [Online]. Available: http://www.gasprocessingnews.com/features/20161 0/optimize-an-integrated-natural-gas-productionand-distribution-network.aspx. [Accessed: 28-Jan2020].

[11] T. Li, P. Liu, and Z. Li, "Modelling and optimization of a natural gas supply system at a transient stage: a case study of China," $B M C$ Energy, vol. 1, no. 1, p. 5, Dec. 2019, doi: 10.1186/s42500-019-0005-6.

[12] W. W. Zhang, B. J. Zhang, C. He, M. Pan, and Q. L. Chen, "Multi-period operational optimization of natural gas treating, blending, compressing, longdistance transmission, and supply network," in Computer Aided Chemical Engineering, vol. 44, M. R. Eden, M. G. Ierapetritou, and G. P. Towler, Eds. Elsevier, 2018, pp. 1249-1254.

[13] M.-W. Fan, J. Gong, Y. Wu, and W.-H. Kong, "The gas supply reliability analysis of natural gas pipeline network based on simplified topological structure," Journal of Renewable and Sustainable Energy, vol. 9, no. 4, p. 045503, Jul. 2017, doi: 10.1063/1.4997490.

[14] R. Zanjirani Farahani, M. Bakhshayeshi Baygi, and S. Mostafa Mousavi, "20 - Risk Management in Gas Networks: A Survey," in Logistics Operations and Management, R. Z. Farahani, S. Rezapour, and L. Kardar, Eds. London: Elsevier, 2011, pp. 421-439.

[15] S. Mokhatab and B. F. Towler, "Dynamic Simulation of Offshore Production Plants," Petroleum Science and Technology, vol. 25, no. 6, pp. 741-757, Jun. 2007, doi: 10.1080/10916460601006131.

[16] A. Herrán-González, J. M. De La Cruz, B. De Andrés-Toro, and J. L. Risco-Martín, "Modeling and simulation of a gas distribution pipeline network," Applied Mathematical Modelling, vol. 33, no. 3, pp. 1584-1600, Mar. 2009, doi: 10.1016/j.apm.2008.02.012.

[17] "VMGThermo ${ }^{\mathrm{TM}}$ | Virtual Materials Group." [Online]. Available: http://dl.virtualmaterials.com/vmgthermo. [Accessed: 28-Jan-2020]. 